\title{
NGHIÊN CÚU MỘT SỐ ĐặC ĐIỂM CỦA CHİ SỐ HUYẾT HỌC Ở BỆNH NHÂN MẮC BỆNH TIM MẠCH NGƯỜI LỚN ĐỰ̛̣C ĐIỀU TRI TẠI TRUNG TÂM TIM MẠCH - BỆNH VIỆN E TỪ NĂM 2019 ĐẾN NĂM 2020
}

Đào Thị Thanh Nga*

\section{TÓM TẮT}

\section{Tổng quan}

Bệnh lý tim mạch người lớn có thể xuất hiện một số thay đổi trên các chỉ số tổng phân tích tế bào máu ngoại vi. Mục tiêu của nghiên cứu: tìm hiểu sự thay đổi của một số chỉ số tổng phân tích tế bào máu ngoại vi ở bệnh nhân mắc bệnh tim mạch người lớn.

\section{Đối tượng và phương pháp}

7038 bệnh nhân người lớn mắc bệnh tim mạch được tiến hành nghiên cứu các chỉ số tế bào máu ngoại vi.

Kết quả: thiếu máu chiếm $28,4 \%$, RDW tăng chiếm $30,4 \%$, số lượng bạch cầu tăng chiếm $15,2 \%$, số lượng bạch cầu trung tính tăng chiếm $26,6 \%$, số lượng tiểu cầu bình thường chiếm 93,6\%. Kết luận: một số thay đổi chỉ số tế bào máu ngoại vi đã được mô tả ở những bệnh nhân người lớn mắc bệnh tim mạch.

STUDY ON SOME CHARACTERISTICS OF THE HEMATOLOGICAL INDICATOR OF ADULT CARDIOVASCULAR DISEASE TREATMENT IN CARDIOVASCULAR CENTER - E HOSPITAL FROM 2019 TO 2020

\section{ABSTRACT:}

Study on peripheral blood cells indices in adult heart patients with cardiovascular disease treated at the Heart Center - Hospital E from 2019 to 2020

\section{Introduction}

In adult cardiovascular disease there may be some changes on the index of peripheral blood cells. Objective: Study on the variation of peripheral blood cell indices in patients with adult cardiovascular disease.

\section{Subjects and methods}

7038 adult patients, who have suffered from cardiovascular disease.

\section{Results}

$28,4 \%$ hypochromic anemia, RDW increased in $30,4 \%$, the $15,2 \%$ of leukocytosis, neutrophils increased in $26,6 \%$, the number of platelets normally accounts in $93,6 \%$.

\section{Conclusion}

Several changes in peripheral blood cell index have been described in adult patients with cardiovascular disease.

Keyword: adult cardiovascular disease, the index of peripheral blood cells.

\section{TỔNG QUAN}

Các bệnh tim mạch bao gồm: các bệnh mạch máu, bệnh cơ tim, loạn nhịp tim, suy tim, bệnh van tim. Bệnh tim mạch có thể xảy ra ở mọi độ tuổi, giới tính, nghề nghiệp. Bệnh không thể chữa khỏi hoàn toàn, đòi hỏi sự điều trị và theo dõi cẩn thận. Tuy nhiên nếu không được phát hiện và điều trị kịp thời sẽ có những biến chứng nặng nề và dẫn đến các nguy cơ tử vong.

Bệnh tim mạch là bệnh lý xuất hiện âm thầm nhưng để lại nhiều hậu quả nghiêm trọng đối với tính mạng. Trong những năm trở lại đây, tỷ lệ tử vong do các bệnh tim mạch ngày một tăng ở các nước đang phát triển, trong đó có Việt Nam, đặc biệt tần suất mắc bệnh tim mạch ngày

* Trung tâm Tim mạch, Bệnh viện E

Nguò̀i chịu trách nhiệm khoa học: Đào Thị Thanh Nga

Ngày nhận bài: 31/12/2020 - Ngày Cho Phép Đăng: 28/01/2021 
càng trẻ hóa do những thói quen thiếu lành mạnh trong sinh hoạt hàng ngày. Bệnh lý tim mạch người lớn thường có những rối loạn trên các cơ quan khác nhau trong đó có các chỉ số huyết học trong xét nghiệm tổng phân tích tế bào máu ngoại vi liên quan đến tỷ lệ mắc bệnh tim mạch. Chính vì vậy nghiên cứu được tiến hành nhằm tìm hiểu một số đặc điểm chỉ số xét nghiệm huyết học ở bệnh nhân người lớn mắc bệnh tim mạch được điều trị tại Trung tâm Tim mạch - Bệnh viện $\mathrm{E}$ từ năm 2019 đến 2020.

\section{II. ĐỐI TƯợNG VÀ PHƯƠNG PHÁP NGHIÊN CÚU}

\section{1. Đối tượng}

7038 bệnh nhân người lớn được chẩn đoán mắc bệnh tim mạch được điều trị tại Trung tâm
Tim mạch - Bệnh viện E, trong đó nam có 3246 bệnh nhân và nữ có 3792 .

\subsection{Phương pháp nghiên cứu}

Sử dụng phương pháp nghiên cứu cắt ngang mô tả.

Các bệnh nhân được lựa chọn vào nghiên cứu được làm xét nghiệm tổng phân tích tế bào máu ngoại vi, các chỉ số này được quan sát và kiểm tra lại trên tiêu bản máu ngoại vi,

Xét nghiệm được tiến hành tại Đơn vị Phát máu và Kiểm soát Đông máu - Trung tâm Tim mạch - Bệnh viện E. Xét nghiệm tổng phân tích tế bào máu ngoại vi được thực hiện trên máy đếm tế bào tự động XT-2000i (SYSMEX. Nhật)

2.3. Xử lý số liệu: bằng phương pháp thống kê y học sử dụng phần mềm SPSS 20.0.

\section{KẾT QUẢ}

\subsection{Phân bố về giới tính}

Bảng 3.1. Phân bố giới tính của bệnh nhân nghiên cưu

\begin{tabular}{|l|c|c|}
\hline Giới tính & Số lượng & Tỷ lệ \% \\
\hline Nam & 3246 & 46,1 \\
\hline Nữ & 3792 & 53,9 \\
\hline Tổng & 7038 & 100,0 \\
\hline
\end{tabular}

Nhận xét: tổng số bệnh nhân nghiên cứu là 7038 bệnh nhân, trong đó nam chiếm 46,1\%, nữ chiếm $53,9 \%$.

\subsection{Phân bố về tuổi}

Bảng 3.2. Phân bố bệnh nhân theo tuổi

\begin{tabular}{|l|c|c|}
\hline \multicolumn{1}{|c|}{ Tuổi } & Số lượng & Tỷ lệ \% \\
\hline Từ 18 đến 49 tuổi & 1585 & 22,5 \\
\hline Từ 50 đến 59 tuổi & 1320 & 18,8 \\
\hline Từ 60 đến 69 tuối & 1984 & 28,2 \\
\hline$\geq 70$ tuổi & 2149 & 30,5 \\
Tổng & 7038 & 100,0 \\
\hline
\end{tabular}

Nhận xét: số bệnh nhân cao tuổi từ 70 tuổi trở lên chiếm 30,5\%, từ 60 đến 69 tuổi chiếm 28,2\%, từ 50 đến 59 tuổi chiếm 18,8\%, số bệnh từ 18 đến 49 tuổi chiếm 22,5\% 


\subsection{Phân bố về bệnh lý}

Bảng 3.3. Phân bố về bệnh lý của bệnh nhân nghiên cưu

\begin{tabular}{|c|l|c|c|}
\hline STT & \multicolumn{1}{|c|}{ Chẩn đoán } & $\begin{array}{c}\text { Số lượng bệnh nhân } \\
(\mathbf{n = 7 0 3 8 )}\end{array}$ & Tỷ lệ \% \\
\hline 1 & Bệnh van tim & 1739 & 24,7 \\
\hline 2 & Bệnh tim bẩm sinh & 384 & 5,5 \\
\hline 3 & Bệnh lý của động mạch chủ & 103 & 1,5 \\
\hline 4 & Bệnh cơ tim, nhịp tim, suy tim & 1385 & 19,7 \\
\hline 5 & Bệnh lý mạch máu ngoại vi và cao huyết áp & 3239 & 46,0 \\
\hline 6 & Nhồi máu cơ tim câp & 188 & 2,7 \\
\hline & Tồng & 7038 & 100,0 \\
\hline
\end{tabular}

Nhận xét: trong số bệnh nhân nghiên cứu bệnh lý về mạch máu ngoại vi và cao huyết áp chiếm tỷ lệ cao nhất là $46 \%$; sau đó là bệnh lý van tim chiếm $24,7 \%$; bệnh lý về cơ tim, nhịp tim, suy tim chiếm tỷ lệ $19,7 \%$; bệnh tim bẩm sinh của người lớn là $5,5 \%$, bệnh lý động mạch chủ là $1,5 \%$, bệnh nhồi máu cơ tim cấp là $2,7 \%$.

\section{4. Đặc điểm về chỉ số hồng cầu}

Bảng 3.4. Đặc điểm về chỉ số hồng cầu ở bệnh nhân nghiên cưu

\begin{tabular}{|c|c|c|c|c|c|c|}
\hline $\begin{array}{l}\text { Chỉ số HC } \\
\text { SLHC }\end{array}$ & $\begin{array}{c}\mathbf{X}^{-} \pm \mathbf{S D} \\
4,589 \pm 0,6771\end{array}$ & $\begin{array}{l}\text { Min } \\
1,460\end{array}$ & \begin{tabular}{|r|} 
Max \\
11,920
\end{tabular} & $\begin{array}{c}\text { Tăng } \\
5,586 \pm 0,6438 \\
(15,0 \%)\end{array}$ & $\begin{array}{c}\text { Giảm } \\
3,683 \pm 0,4003 \\
(17,8 \%)\end{array}$ & $\begin{array}{c}\text { Bình thường } \\
4,607 \pm 0,3286 \\
(67,2 \%)\end{array}$ \\
\hline SLHC Nam & $4,744 \pm 0,7215$ & 1,730 & 11,920 & & & \\
\hline SLHC Nũ & $4,456 \pm 0,7215$ & 1,460 & 9,770 & & & \\
\hline $\begin{array}{l}\text { Hemoglobin } \\
(\mathrm{g} / \mathrm{dl})\end{array}$ & $13,414 \pm 1,7926$ & 4,4 & 25,9 & $\begin{array}{c}16,005 \pm 1,4157 \\
(10,1 \%)\end{array}$ & $\begin{array}{c}11,338 \pm 1,2591 \\
(28,4 \%)\end{array}$ & $\begin{array}{c}13,949 \pm 0,8904 \\
(61,6 \%)\end{array}$ \\
\hline $\begin{array}{l}\text { Hemoglobin } \\
\text { Nam }(g / d l)\end{array}$ & $14,032 \pm 1,8839$ & 5,2 & 25,9 & & & \\
\hline $\begin{array}{l}\text { Hemoglobin Nữ } \\
(\mathrm{g} / \mathrm{dl})\end{array}$ & $12,882 \pm 1,5208$ & 4,4 & 21,5 & & & \\
\hline Hematocrit (\%) & $40,16 \pm 4,979$ & 16,2 & 75,4 & $\begin{array}{c}46,04 \pm 4,041 \\
(14,9 \%)\end{array}$ & $\begin{array}{c}34,65 \pm 3,760 \\
(28,6 \%)\end{array}$ & $\begin{array}{c}41,39 \pm 2,535 \\
(56,5 \%)\end{array}$ \\
\hline $\begin{array}{l}\text { Hematocrit } \\
\operatorname{Nam}(\%)\end{array}$ & $41,71 \pm 5,269$ & 15,0 & 65,4 & & & \\
\hline $\begin{array}{l}\text { Hematocrit Nữ } \\
(\%)\end{array}$ & $38,82 \pm 4,287$ & 15,0 & 75,4 & & & \\
\hline MCV (fl) & $88,09 \pm 7,440$ & 119,1 & 44,4 & $\begin{array}{c}102,98 \pm 2,987 \\
(1,4 \%)\end{array}$ & $\begin{array}{c}70,06 \pm 6,665 \\
(9,5 \%)\end{array}$ & $\begin{array}{c}89,77 \pm 4,052 \\
(89,1 \%)\end{array}$ \\
\hline $\mathrm{MCH}(\mathrm{pg})$ & $29,41 \pm 2,744$ & 44,9 & 15,1 & $\begin{array}{c}32,97 \pm 1,082 \\
(9,2 \%)\end{array}$ & $\begin{array}{c}24,66 \pm 2,899 \\
(16,8 \%)\end{array}$ & $\begin{array}{c}30,04 \pm 1,018 \\
(74,0 \%)\end{array}$ \\
\hline $\mathrm{MCHC}$ & $33,37 \pm 1,039$ & 45,3 & 26,0 & $\begin{array}{c}36,884 \pm 1,7291 \\
(0,7 \%\end{array}$ & $\begin{array}{c}31,301 \pm, 7832 \\
(7,1 \%)\end{array}$ & $\begin{array}{c}33,503 \pm, 8162 \\
(92,3 \%)\end{array}$ \\
\hline RDW (\%) & $13,877 \pm 1,823$ & 10,7 & 33,8 & $\begin{array}{c}15,81 \pm 2,195 \\
(30,4 \%)\end{array}$ & $10,70(0,0 \%)$ & $\begin{array}{c}13,03 \pm 0,564 \\
(69,6 \%)\end{array}$ \\
\hline
\end{tabular}


Nhận xét:

Số lượng hồng cầu trung bình ở bệnh nhân nghiên cứu là 4,589 $\pm 0,6771 \mathrm{~T} / \mathrm{L}$ và cao nhất là $11,920 \mathrm{~T} / \mathrm{L}$, thấp nhất là $1,460 \mathrm{~T} / \mathrm{L}$, trong đó ở bệnh nhân nam là 4,744 $\pm 0,7215 \mathrm{~T} / \mathrm{L}$, ở bệnh nhân nữ là 4,456 $\pm 0,6053 \mathrm{~T} / \mathrm{L}$ với $\mathrm{p}<0,05$. Trong đó số lượng hồng cầu thấp là $3,683 \pm 0,4003 \mathrm{~T} / \mathrm{L}$ chiếm $17,8 \%$, số lượng hồng cầu bình thường là $4,607 \pm 0,3286 \mathrm{~T} / 1$ chiếm $67,2 \%$, số lượng hồng cầu cao là $5,586 \pm 0,6438 \mathrm{~T} / \mathrm{L}$ chiếm $15 \%$.

Huyết sắc tố trung bình ở bệnh nhân nghiên cứu là $14,03 \pm 1,792 \mathrm{~g} / \mathrm{dL}$ và cao nhất là $25,9 \mathrm{~g} / \mathrm{dL}$, thấp nhất là $4,4 \mathrm{~g} / \mathrm{dL}$, trong đó ở bệnh nhân nam là $14,03 \pm 1,883 \mathrm{~g} / \mathrm{dL}$, ở bệnh nhân nữ là $12,88 \pm 1,520 \mathrm{~g} / \mathrm{dL}$ với $\mathrm{p}<0,05$. Tỷ lệ thiếu máu là $28,4 \%$.

Hematocrit trung bình ở bệnh nhân nghiên cứu là $40,16 \pm 4,979 \%$ và cao nhất là $75,4 \%$, thấp nhất là $15,0 \%$, trong đó ở bệnh nhân nam là 41,71 $\pm 5,269 \%$, ở bệnh nhân nữ là $38,82 \pm 4,287 \%$, với $\mathrm{p}<0,05$.

Độ phân bố hồng cầu: chỉ số RDW bình thường là $13,03 \pm 0,564 \%$, chiếm $69,6 \%$; RDW cao là $15,81 \pm 2,195 \%$, chiếm 30,4\%.

$\mathrm{MCV}$

\section{5. Đặc điểm về chỉ số bạch cầu}

Bảng 3.5. Đặc điểm về số lương bạch cầu ở nhóm bệnh nhân nghiên cứu

\begin{tabular}{|c|c|c|c|c|c|c|c|}
\hline $\begin{array}{c}\text { Chỉ số } \\
\text { BC (G/l) }\end{array}$ & $\mathbf{X}^{-} \pm \mathbf{S D}$ & Min & Max & Tăng & Giảm & Bình thường & $\mathbf{p}$ \\
\hline SLBC & $7,877 \pm 3,5398$ & 1,52 & 143,50 & $\begin{array}{c}13,345 \pm 5,8810 \\
(15,2 \%)\end{array}$ & $\begin{array}{c}3,442 \pm 0,5573 \\
(1,6 \%)\end{array}$ & $\begin{array}{c}6,9621 \pm 1,4307 \\
(83,2 \%)\end{array}$ & $<0,05$ \\
\hline BCTT & $4,922 \pm 3,0208$ & 0,470 & 103,520 & $\begin{array}{c}8,257 \pm 3,8122 \\
(26,6 \%)\end{array}$ & $\begin{array}{c}2,337 \pm 0,3787 \\
(14,3 \%)\end{array}$ & $\begin{array}{c}4,044 \pm 1,2126 \\
(26,6 \%)\end{array}$ & $<0,05$ \\
\hline Lympho & $2,060 \pm 0,9080$ & 0,160 & 45,410 & $\begin{array}{c}3,627 \pm 1,6783 \\
(9,8 \%)\end{array}$ & $\begin{array}{c}0,932 \pm 0,2198 \\
(10,7 \%)\end{array}$ & $\begin{array}{c}2,018 \pm 0,4556 \\
(79,5 \%)\end{array}$ & $<0,05$ \\
\hline BC mono & $0,640 \pm 0,4846$ & 0,020 & 0,0400 & $\begin{array}{c}0,707 \pm 0,5060 \\
(82,8 \%)\end{array}$ & $\begin{array}{c}0,033 \pm 0,0081 \\
(0,1 \%)\end{array}$ & $\begin{array}{c}0,315 \pm, 0668 \\
(17,1 \%)\end{array}$ & $<0,05$ \\
\hline $\begin{array}{l}\text { BC ưa } \\
\text { acid }\end{array}$ & $0,222 \pm 0,3463$ & 0,000 & 16,810 & & & & \\
\hline $\begin{array}{l}\text { BC ura } \\
\text { base }\end{array}$ & $0,030 \pm 0,0397$ & 0.000 & 1,260 & & & & \\
\hline
\end{tabular}

Nhận xét:

Số lượng bạch cầu trung bình là 7,877 $\pm 3,5398 \mathrm{G} / 1$. Số lượng bạch cầu giảm là $3,442 \pm 0,5573$ G/1 chiếm $1,6 \%$, số lượng bạch cầu bình thường là $6,962 \pm 1,4307$ G/1 chiếm $83,2 \%$, số lượng bạch cầu cao là 13,345 $\pm 5,8809 \mathrm{G} / 1$ chiếm 15,2\%.

Số lượng bạch cầu trung tính trung bình là 4,922 $\pm 3,0208 \mathrm{G} /$ 1Số lượng bạch cầu trung tính giảm là $2,337 \pm 0,3787 \mathrm{G} / 1$ chiếm $14,3 \% \mathrm{G} / 1$, số lượng bạch cầu trung tính bình thường là 4,044 $\pm 1,2126$ G/1 chiếm $59,1 \%$, số lượng bạch cầu trung tính tăng là $8,257 \pm 3,8122 \mathrm{G} / 1$ chiếm $26,6 \%$.

Số lượng bạch cầu lympho giảm là $0,932 \pm 0,2198 \mathrm{G} / 1$ chiếm $10,7 \% \mathrm{G} / 1$, số lượng bạch cầu lympho bình thường là $2,018 \pm 0,4556 \mathrm{G} / 1$ chiếm $79,5 \%$, số lượng bạch cầu lympho tăng là $3,627 \pm$ 1,6783 G/1 chiếm 9,8\%. 


\subsection{Số lượng tiểu cầu}

Bảng 3.6. Đặc điểm về số lượng tiểu cầu ở bệnh nhân nghiên cưu

\begin{tabular}{|l|c|c|c|c|c|}
\hline Số lượng tiểu cầu & Số lượng & Tỷ lệ \% & Trung bình & Max & Min \\
\hline$<150 \mathrm{G} / 1$ & 340 & $4,7 \%$ & $118,0 \pm 27,96$ & 149 & 14 \\
\hline $150-400 \mathrm{G} / 1$ & 6817 & $93,6 \%$ & $259,3 \pm 59,53$ & 450 & 150 \\
\hline$>400 \mathrm{G} / 1$ & 124 & $1,7 \%$ & $530,9 \pm 121,95$ & 1065 & 74 \\
\hline Tổng & 7281 & $100,0 \%$ & $257,3 \pm 76,10$ & 1065 & 14 \\
\hline
\end{tabular}

Nhận xét: số lượng tiểu cầu trung bình là $257,3 \pm 76,10 \mathrm{G} / 1$, số lượng tiểu cầu thấp là $118,0 \pm$ $27,96 \mathrm{G} / 1$ chiếm $4,7 \%$, số lượng tiểu cầu bình thường là $259,3 \pm 59,53 \mathrm{G} / 1$ chiếm $93,6 \%$, số lượng tiểu cầu cao là $530,9 \pm 121,95 \mathrm{G} / 1$ chiếm $1,7 \%$.

\section{BÀN LUÂN}

Tổng số bệnh nhân nghiên cứu là 7038 bệnh nhân, trong đó nam chiếm $46,1 \%$, nữ chiếm $53,9 \%$.

Phân bố bệnh tật bệnh lý về mạch máu ngoại vi và cao huyết áp chiếm tỷ lệ cao nhất là $46 \%$; sau đó là bệnh lý van tim chiếm $24,7 \%$; bệnh lý về cơ tim, nhịp tim, suy tim chiếm tỷ lệ 19,7\%; bệnh tim bẩm sinh của người lớn là $5,5 \%$, bệnh lý động mạch chủ là $1,5 \%$, bệnh nhồi máu cơ tim cấp là $2,7 \%$.

Các bệnh nhân mắc bệnh lý tim mạch thường có các bệnh khác đi kèm. Các thay đổi về huyết học có thể là nguyên nhân của rối loạn, nhưng chúng cũng có thể là kết quả của sự tưới máu mô kém [1]. Thiếu máu do giảm nồng độ hemoglobin gây ra tình trạng thiếu ô xy, biến đổi huyết động và bù trừ huyết động cơ học. Hậu quả của sự bù trừ tim mạch trong thiếu máu bao gồm nhịp tim nhanh, tăng cung lượng tim, giãn mạch tạo điều kiện cho tưới máu mô. Các thay đổi lâm sàng và huyết động do thiếu máu cấp tính có thể phục hồi được, nhưng thiếu máu mãn tính dẫn đến phì đại cơ tim tiến triển và phì đại thất trái do quá tải thể tích tuần hoàn [2]. Tình trạng thiếu oxy ở mô và những thay đổi trong mô hình dòng chảy của máu do hemoglobin thấp có thể đóng vai trò gây xơ vữa [2].

Thiếu máu là một bệnh đi kèm thường gặp ở bệnh nhân suy tim mãn tính và có liên quan đến tăng tỷ lệ tử vong do mọi nguyên nhân và tim mạch, giảm khả năng gắng sức do giảm khả năng vận chuyển và dự trữ oxy, giảm chất lượng cuộc sống, nguy cơ nhập viện cao hơn [3] [4].

Số lượng hồng cầu trung bình ở bệnh nhân nghiên cứu là $4,589 \pm 0,6771 \mathrm{~T} / 1$ và cao nhất là 11,920 T/1, thấp nhất là $1,460 \mathrm{~T} / 1$, trong đó ở bệnh nhân nam là $4,744 \pm 0,7215 \mathrm{~T} / 1$, ở bệnh nhân nữ là $4,456 \pm 0,6053 \mathrm{~T} / 1$ với $\mathrm{p}<0,05$. Chỉ số về số lượng hồng cầu trong nghiên cứu của chúng tôi tương đương với nghiên cứu của Nguyễn Quang Tùng (4,62 $\pm 0,56$ T/1) [5]. Trong đó số lượng hồng cầu thấp là $3,683 \pm 0,4003 \mathrm{~T} / \mathrm{L}$ chiếm $17,8 \%$, số lượng hồng cầu bình thường là $4,607 \pm$ $0,3286 \mathrm{~T} / 1$ chiếm $67,2 \%$, số lượng hồng cầu cao là $5,586 \pm 0,6438 \mathrm{~T} / \mathrm{L}$ chiếm $15 \%$. Những trường hợp số lượng hồng cầu cao gặp trong bệnh lý tim bẩm sinh có tím là một sự đáp ứng của cơ thể với tình trạng thiếu oxy ở mô làm kích thích tiết erythropoinetin làm tăng sản xuất hồng cầu gây ra tình trạng đa hồng cầu thứ phát.

Hemoglobin trung bình của bệnh nhân nghiên cứu là $13,41 \pm 1,792 \mathrm{~g} / \mathrm{dl}$ ở bệnh nhân nam là $14,03 \pm 1,883 \mathrm{~g} / \mathrm{dl}$, ở bệnh nhân nữ là $12,88 \pm 1,520 \mathrm{~g} / \mathrm{dl}$. Tỷ lệ thiếu máu là $28,4 \%$, tương đương với nghiên cứu của Yi-Da Tang [6], James B Young [3]. Theo nghiên cứu của Yi-Da Tang and Stuart D. Katz [6] thì tỷ lệ thiếu máu ở bệnh nhân suy tim mãn tính trung bình $18 \%$, tỷ lệ thiếu máu này tăng lên khi có bệnh thận kèm 
theo, tuổi cao và các triệu chứng nghiêm trọng hơn từ $30 \%$ đến $61 \%$.Theo nghiên cứu của $\underline{\mathrm{James}}$ B Young [3] ở bệnh nhân suy tim có tỷ lệ $25 \%$ bệnh nhân thiếu máu từ trung bình đến thiếu máu nặng thường gặp ở bệnh nhân lớn tuổi hơn, và ở phụ nữ nhiều hơn. Chỉ số về hemoglobin trung bình trong nghiên cứu của chúng tôi tương đương với nghiên cứu của Nguyễn Quang Tùng $(14,14 \pm$ $1,82 \mathrm{~g} / \mathrm{dl}$ ) [5].

Độ phân bố hồng cầu RDW, là một chỉ số của công thức máu hoàn chỉnh tiêu chuẩn là thước đo các biến thể về thể tích của tế bào hồng cầu. Sự gia tăng trong RDW được gọi là chứng tăng tế bào máu. Mức độ RDW tăng lên đã được tìm thấy ở những bệnh nhân thiếu hụt vitamin $\mathrm{B} 12$, sắt và folate. RDW cũng đã được quan sát thấy sau khi truyền máu và tán huyết [6].

Trong nghiên cứu của chúng tôi chỉ số RDW bình thường là $13,03 \pm 0,564 \%$, chiếm $69,6 \%$; RDW cao là $15,81 \pm 2,195 \%$, chiếm $30,4 \%$. Trong nghiên cứu của Patel và cộng sự, giá trị RDW trên $14,0 \%$ có liên quan đáng kể đến việc giảm khả năng biến dạng của tế bào hồng cầu, có thể làm giảm lưu lượng máu qua vi tuần hoàn. Kết quả là sự giảm cung cấp oxy ở cấp độ mô có thể giúp giải thích nguy cơ tăng các biến cố tim mạch có hại liên quan đến RDW tăng cao[7]. Năm 2007, Felker là một trong những tác giả đầu tiên chứng minh rằng $\mathrm{RDW}$ tăng cao là một dấu ấn sinh học hữu ích về bệnh tật và tử vong ở bệnh nhân suy tim [8]. Trong nghiên cứu của Arbel và cộng sự, mức $\mathrm{RDW}$ từ $17 \%$ trở lên có liên quan đến tăng nguy cơ mắc bệnh tim mạch và tử vong do mọi nguyên nhân ở cả bệnh nhân thiếu máu và không thiếu máu [9]. Tonelli và cộng sự. chỉ ra mối quan hệ giữa mức $R D W$ cao hơn với nguy cơ tử vong và các kết cục bất lợi về tim mạch ở những người bị nhồi máu cơ tim trước đó nhưng không có triệu chứng suy tim [10] . Hơn nữa, nó được chỉ ra rằng $\mathrm{RDW}$ tăng cao có liên quan đến tỷ lệ tử vong cao hơn ở những bệnh nhân bị nhồi máu cơ tim (có hoặc không có thiếu máu) [11]. Nhiều nghiên cứu đã nhấn mạnh rằng RDW tăng lên cũng có liên quan đến bệnh động mạch ngoại vi [12], tăng áp động mạch phổi [11]. Hơn nữa, nó được chỉ ra rằng RDW tăng cao có liên quan đến tỷ lệ tử vong cao hơn ở những bệnh nhân bị nhồi máu cơ tim (có hoặc không có thiếu máu) [12]. Người có $\mathrm{MCV}$ và $\mathrm{RDW}$ lớn hơn có nguy cơ mắc bệnh tim mạch cao hơn[13].

Bạch cầu: Số lượng bạch cầu trong nghiên cứu của chúng tôi là $7,877 \pm 3,5398 \mathrm{G} / 1$, trong đó số lượng bạch cầu cao là $13,345 \pm 5,8809 \mathrm{G} / 1$ chiếm $15,2 \%$. Số lượng bạch cầu trung tính là $4,922 \pm 3,0208 \mathrm{G} / 1$ số lượng bạch cầu trung tính tăng là $8,257 \pm 3,8122 \mathrm{G} / 1$ chiếm $26,6 \%$. Số lượng bạch cầu lympho là $0,932 \pm 0,2198 \mathrm{G} / 1$. Trong một nghiên cứu của $\mathrm{CP}$ Cannon cho thấy rằng $\mathrm{WBC}>10.000$ chỉ ra tỷ lệ tử vong ở bệnh nhân nhồi máu cơ tim cấp tăng lên. [14].

Số lượng tế bào bạch huyết có liên quan đến nguy cơ bệnh tim mạch [15] và bệnh lý tim mạch [16]. Bạch cầu đóng một vai trò quan trọng trong sinh lý bệnh của hội chứng mạch vành cấp tính, do ảnh hưởng của chúng đối với sự mất ổn định của các mảng xơ vữa động mạch. tăng bạch cầu cũng được chứng minh là có giá trị tiên lượng khi đánh giá các kết cục lâm sàng bất lợi [16].

Tiểu cầu: Trong nghiên cức của chúng tôi số lượng tiểu cầu trung bình là $257,3 \pm 76,10 \mathrm{G} / 1$, số lượng tiểu cầu cao là $530,9 \pm 121,95 \mathrm{G} / 1$ chiếm $1,7 \%$. Số lượng tiểu cầu bình thường là $259,3 \pm$ $59,53 \mathrm{G} / 1$ chiếm $93,6 \%$, Số lượng tiểu cầu tăng nhiều nhất trong các trường hợp bệnh lý mạch máu đặc biệt là bệnh lý mạch vành.

Bất kể vai trò của chúng trong phản ứng viêm nói chung (toàn thân), tiểu cầu có liên quan chặt chẽ đến sự hoạt hóa và điều phối của nội mô. Jan Budzianowski đã quan sát thấy rằng có mối liên quan chặt chẽ giữa tỷ lệ tử vong do tim mạch và số lượng tiểu cầu hoặc khả năng kết tụ của chúng [1]. Tiểu cầu đóng một vai trò quan trọng trong sinh lý bệnh của hội chứng mạch vành cấp $\mathrm{ACS}$. Kết hợp với fibrin, tiểu cầu tạo thành huyết khối mạch vành [1]. Tiểu cầu tham 
gia vào việc tạo cục máu đông và cung cấp các chất trung gian phát triển và duy trì phản ứng viêm tại chỗ [14]. MPV và $\mathrm{PDW}$ là những dấu hiệu quan trọng và đơn giản, tăng đáng kể trong quá trình hoạt hóa tiểu cầu [15]. Hơn nữa, các chỉ số này rất hữu ích trong việc đánh giá các bệnh huyết khối tắc mạch.

\section{KẾT LUẬN}

Qua khảo sát 7038 bệnh nhân bệnh lý tim mạch chúng tôi rút ra một số kết luận sau:

Số lượng hồng cầu trung bình ở bệnh nhân nghiên cứu là 4,589 $\pm 0,6771 \mathrm{~T} / 1$

Hemoglobin trung bình của bệnh nhân nghiên cứu là $13,41 \pm 1,792 \mathrm{~g} / \mathrm{d} 1$. Tỷ lệ thiếu máu là $28,4 \%$ trường hợp. RDW cao là $15,81 \pm$ 2,195\%, chiếm 30,4\%.

Số lượng bạch cầu là $7,877 \pm 3,5398$ G/1, số lượng bạch cầu tăng chiếm $15,2 \%$ chủ yếu là tăng bạch cầu trung tính. Số lượng bạch cầu trung tính tăng chiếm $26 \mathrm{SS}, 6 \%$ trong số bệnh nhân nghiên cứu.

Số lượng tiểu cầu bình thường 259,3 $\pm 59,53$ G/1 chiếm 93,6\%.

\section{TÀI TIẸU THAM KHẢO}

1. Budzianowski J, Pieszko K, Burchardt P, Rzeźniczak J, Hiczkiewicz J. The Role of Hematological Indices in Patients with Acute Coronary Syndrome [Internet]. Vol. 2017, Disease Markers. Hindawi; 2017 [cited 2021 Jan 28]. p. e3041565. Available from: https://www.hindawi.com/journals/dm/2017/30 41565/

2. Metivier F, Marchais SJ, Guerin AP, Pannier B, London GM. Pathophysiology of anaemia: focus on the heart and blood vessels. Nephrol Dial Transplant. 2000 Sep 2;15(suppl_3):14-8.

3. Yancy CW, Jessup M, Bozkurt B, Butler J, Casey DE, Drazner MH, et al. 2013 ACCF/AHA Guideline for the Management of
Heart Failure: A Report of the American College of Cardiology Foundation/American Heart Association Task Force on Practice Guidelines. Journal of the American College of Cardiology. 2013 Oct 15;62(16):e147-239.

4. Dabbah S, Hammerman H, Markiewicz W, Aronson D. Relation Between Red Cell Distribution Width and Clinical Outcomes After Acute Myocardial Infarction. American Journal of Cardiology. 2010 Feb 1;105(3):312-7.

5. E S, S T, M U. Important details about the red cell distribution width [Internet]. Vol. 22, Journal of atherosclerosis and thrombosis. J Atheroscler Thromb; 2015 [cited 2021 Jan 28]. Available from: https://pubmed.ncbi.nlm.nih.gov/25747554/

6. Tang Yi-Da, Katz Stuart D. Anemia in Chronic Heart Failure. Circulation. 2006 May 23;113(20):2454-61.

7. Kv P, Jg M, B K, C H, Wb E, Jm R. Association of the red cell distribution width with red blood cell deformability [Internet]. Vol. 765, Advances in experimental medicine and biology. Adv Exp Med Biol; 2013 [cited 2021 Jan 28]. Available from: https://pubmed.ncbi.nlm.nih.gov/22879035/

8. Gm F, La A, Sj P, Lk S, Jj M, Ma P, et al. Red cell distribution width as a novel prognostic marker in heart failure: data from the CHARM Program and the Duke Databank [Internet]. Vol. 50, Journal of the American College of Cardiology. J Am Coll Cardiol; 2007 [cited 2021 Jan 28]. Available from: https://pubmed.ncbi.nlm.nih.gov/17601544/

9. Y A, D W, R R, A S, D Z, S B, et al. Red blood cell distribution width and the risk of cardiovascular morbidity and all-cause mortality. A population-based study [Internet]. Vol. 111, Thrombosis and haemostasis. Thromb Haemost; 2014 [cited 2021 Jan 28]. Available from: https:/pubmed.ncbi.nlm.nih.gov/24173039/ 
10. T I, M K, E A, Ih T, M E, H U. The impact of admission red cell distribution width on the development of poor myocardial perfusion after primary percutaneous intervention [Internet]. Vol. 224, Atherosclerosis. Atherosclerosis; 2012 [cited 2021 Jan 28]. Available https://pubmed.ncbi.nlm.nih.gov/22748279/ from:

11. Cv H, Ak M, T T, M G-M, Sj S. Usefulness of red cell distribution width as a prognostic marker in pulmonary hypertension [Internet]. Vol. 104, The American journal of cardiology. Am J Cardiol; 2009 [cited 2021 Jan 28]. Available from: https:/pubmed.ncbi.nlm.nih.gov/19733726/

12. Ye Z, Smith C, Kullo IJ. Usefulness of red cell distribution width to predict mortality in patients with peripheral artery disease. Am J Cardiol. 2011 Apr 15;107(8):1241-5.
13. Grau AJ, Boddy AW, Dukovic DA, Buggle F, Lichy C, Brandt T, et al. Leukocyte count as an independent predictor of recurrent ischemic events. Stroke. 2004 May;35(5):1147-52.

14. Croce $K$, Libby $P$. Intertwining of thrombosis and inflammation in atherosclerosis. Current Opinion in Hematology. 2007 Jan;14(1):55-61.

15. Vagdatli E, Gounari E, Lazaridou E, Katsibourlia E, Tsikopoulou F, Labrianou I. Platelet distribution width: a simple, practical and specific marker of activation of coagulation. Hippokratia. 2010 Jan;14(1):28-32.

16. Lassale C, Curtis A, Abete I, van der Schouw YT, Verschuren WMM, Lu Y, et al. Elements of the complete blood count associated with cardiovascular disease incidence: Findings from the EPIC-NL cohort study. Sci Rep. 2018 Feb 19;8(1):3290. 